\title{
True Power Loss Reduction by Chemical Reaction Optimization Algorithm
}

\author{
Kanagasabai Lenin
}

Department of EEE, Prasad V. Potluri Siddhartha Institute of Technology, Kanuru, Vijayawada, Andhra Pradesh 520007, India

Corresponding Author Email: gklenin@gmail.com

https://doi.org/10.18280/ejee.210209

Received: 17 January 2019

Accepted: 16 March 2019

\section{Keywords:}

optimal reactive power, transmission loss, chemical reaction

\begin{abstract}
In this paper Chemical Reaction Optimization (CRO) algorithm is proposed to solve the optimal reactive power problem. Molecules are encoded as candidate solution in the projected algorithm. Molecular structure $(\varphi)$, potential energy (PY), kinetic energy (KE) and numerous crucial properties possessed by the Chemical Reaction Optimization (CRO) algorithm. With minimal potential energy (PE) reactants are leaning to unwavering product. Gaussian perturbations with reflection, half-total change, laws of conservation of energy are form as the prime operators in the Chemical Reaction Optimization (CRO) algorithm. In the evolution of the algorithm structure manage the least potential energy (PE). Potential energy (PE) is kept as the objective function of the analogous solution. Projected Chemical Reaction Optimization (CRO) algorithm has been tested in standard IEEE 14, 57, 300 bus systems. Simulation results indicate the better performance of the proposed algorithm in reducing the real power loss.
\end{abstract}

\section{INTRODUCTION}

$\mathrm{T}$ Reactive power problem plays a key role in secure and economic operations of power system. Optimal reactive power problem has been solved by a various type of methods [1-8]. Nevertheless numerous scientific difficulties are found while solving problem due to an assortment of constraints. Evolutionary techniques [9-21] are applied to solve the reactive power problem. In this paper Chemical Reaction Optimization (CRO) algorithm is proposed to solve the optimal reactive power Problem. CRO algorithm has productively solved many multifaceted problems and the optimal solution is better than assortment of intelligent algorithms. In this work regulate molecular structure and energy management has been utilized in the formulation of the algorithm. Candidate solution of reactive power flow problem is encoded as a molecule in Chemical Reaction Optimization (CRO) algorithm. Molecular structure $(\varphi)$, potential energy (PE), kinetic energy (KE) are some numerous crucial properties possessed by the algorithm. Reactants are leaning to stable product with the minimal potential energy (PE) in the algorithm. Structure reaches the least potential energy (PE) in the evolution of the algorithm. In this work Chemical Reaction Optimization (CRO) algorithm has been tested in standard IEEE 14, 57, 300 bus systems. Simulation results indicate the better performance of the proposed algorithm in reducing the real power loss.

\section{PROBLEM FORMULATION}

Objective of the problem is to reduce the true power loss:

$$
\mathbf{F}=\mathbf{P}_{\mathrm{L}}=\sum_{\mathrm{k} \in \mathrm{Nbr}} \mathbf{g}_{\mathrm{k}}\left(\mathbf{V}_{\mathrm{i}}^{2}+\mathrm{V}_{\mathrm{j}}^{2}-2 \mathrm{~V}_{\mathrm{i}} \mathbf{V}_{\mathrm{j}} \cos \theta_{\mathrm{ij}}\right)
$$

Voltage deviation given as follows:

$$
F=P_{L}+\omega_{v} \times \text { Voltage Deviation }
$$

Voltage deviation given by:

$$
\text { Voltage Deviation } \quad=\sum_{\mathrm{i}=1}^{\mathrm{Npq}}\left|\mathbf{V}_{\mathbf{i}}-\mathbf{1}\right|
$$

Constraint (Equality)

$$
\mathbf{P}_{\mathrm{G}}=\mathbf{P}_{\mathrm{D}}+\mathbf{P}_{\mathbf{L}}
$$

Constraints (Inequality)

$$
\begin{aligned}
& \mathbf{P}_{\text {gslack }}^{\min } \leq \mathbf{P}_{\text {gslack }} \leq \mathbf{P}_{\text {gslack }}^{\max } \\
& \mathbf{Q}_{\mathrm{gi}}^{\min } \leq \mathbf{Q}_{\mathrm{gi}} \leq \mathbf{Q}_{\mathrm{gi}}^{\max }, \mathbf{i} \in \mathbf{N}_{\mathrm{g}} \\
& \mathbf{V}_{\mathbf{i}}^{\min } \leq \mathbf{V}_{\mathbf{i}} \leq \mathbf{V}_{\mathbf{i}}^{\max }, \mathbf{i} \in \mathbf{N} \\
& \mathbf{T}_{\mathrm{i}}^{\min } \leq \mathrm{T}_{\mathrm{i}} \leq \mathrm{T}_{\mathrm{i}}^{\max }, \mathbf{i} \in \mathrm{N}_{\mathrm{T}} \\
& \mathbf{Q}_{c}^{\text {min }} \leq \mathbf{Q}_{c} \leq \mathbf{Q}_{\mathbf{C}}^{\max }, \mathbf{i} \in \mathbf{N}_{\mathrm{C}}
\end{aligned}
$$

\section{CHEMICAL REACTION OPTIMIZATION ALGORITHM}

Chemical Reaction Optimization (CRO) algorithm has been formulated to solve the reactive power optimization problem. Molecules are encoded as candidate solution in the projected algorithm. Molecular structure $(\varphi)$, potential energy (PE), kinetic energy (KE) and numerous crucial properties possessed by the Chemical Reaction Optimization (CO) algorithm. With minimal potential energy (PE) reactants are leaning to unwavering product. In the evolution of the algorithm structure manage the least potential energy (PE). Potential energy (PE) is kept as the objective function of the analogous solution and it symbolized by $\varphi$ as follow, 


$$
P E(\varphi)=f(\varphi)
$$

The molecule class algorithm can be written as

Category Molecule

Characteristics:

Molecular structure ( $\omega$ ), PE (potential energy), KE (kinetic energy), Number of Hit, Minimum Structure, Minimum PE, Minimum number of Hit

Technique:

Molecule () \I ctor

\{

Arbitrarily engender $\omega$ in the solution space

Potential energy $\leftarrow f(\omega)$

Kinetic energy $\leftarrow$ preliminary value of kinetic energy

Number of Hit $\leftarrow 0$

Minimum Structure $\leftarrow \omega$

Minimum potential energy $\leftarrow P E$

Minimum number of Hit

$\leftarrow 0$

\}

On wall Ineffective Collision ( )

Decomposition ( )

Intermolecular Ineffective Collision ( )

Synthesis ( )

End class

Collision is the main cause of the chemical reaction. Four elementary reactions: molecule collision, decomposition, molecular collision and synthesis are form as the basics of the algorithm. Pop size ( ), Molecule Collusion, KE Loss Rate, Initial KE, buffer, $\gamma, \delta$ are basic parameters of the algorithm. Gaussian perturbations with reflection, half-total change, laws of conservation of energy are form as the prime operators [22] in the Chemical Reaction Optimization (CRO) algorithm;

$$
\begin{gathered}
\sum_{k=1}^{k=p o p s i z e}(t) P E_{\omega}(k)+K E_{\omega}(k)+b u f f e r(k)==C \\
\sum_{k=1}^{k=C} P E_{\omega}+K E_{\omega} \geq \sum_{k=1}^{k=l} P E_{\omega}^{\prime}
\end{gathered}
$$

By on-wall ineffective collision, decomposition, intermolecular ineffective collision and synthesis operation algorithm has been employed.

Molecular wall operation: In a single molecule a small change in the molecular structure in the independent space. The equivalent of the target function under the condition of conservation of energy in any adjacent area search is $P E_{\varphi}^{\prime}=$ $f\left(\varphi^{\prime}\right)$.

For illustration:

$$
\text { out }(m, n)=i n+\text { random } n
$$

Algorithm for Molecular wall ineffective collusion Input: molecule $M_{\omega}$

$\omega \leftarrow N(\omega)$

$P E_{\omega^{\prime}} \leftarrow f\left(\omega^{\prime}\right)$

Number of Hit $\omega_{\omega} \leftarrow$ Number of Hit $_{\omega}+1$

If $P E \omega+K E \omega \geq P E_{\omega^{\prime}}$ then

Engender $a \in[K E$ Loss Rate, 1]

$K E_{\omega^{\prime}} \leftarrow\left(P E \omega-P E_{E}+K E \omega\right) \times a$

Buffer $\leftarrow$ buffer $+\left(P E \omega-P E_{\omega^{\prime}}+K E \omega\right) \times(1-a)$

$\omega \leftarrow \omega^{\prime}$

$P E \omega \leftarrow P E_{\omega^{\prime}}$

$K E \omega \leftarrow K E_{\omega^{\prime}}$

If $P E \omega<$ Minimum $P E \omega$ then
Minimum Structure $\omega \leftarrow \omega$

Minimum $P E \omega \leftarrow P E \omega$

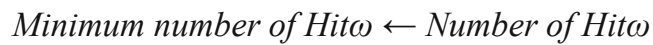

End if

End if

Decomposition operation: when a molecule encounters a collision and then it decomposes into two molecules. It is equated with the following,

$$
f(\varphi) \geq f\left(\varphi_{1}^{\prime}\right)+f\left(\varphi_{2}^{\prime}\right)
$$

Algorithm for decomposition

Input: molecule $M \omega$

Generate $M_{\omega_{1}^{\prime}}$ and $M_{\omega_{2}^{\prime}}$

Acquire $\omega_{1}^{\prime}$ and $\omega_{2}^{\prime}$ from $\omega$

$P E_{\omega_{1}^{\prime}} \leftarrow f\left(\omega_{1}^{\prime}\right)$ and $P E_{\omega_{2}^{\prime}} \leftarrow f\left(\omega_{2}^{\prime}\right)$

If $P E \omega+K E \omega \geq P E_{\omega_{1}^{\prime}}+P E_{\omega_{2}^{\prime}}$ then

$E d e c \leftarrow P E \omega+K E \omega-\left(P E_{\omega_{1}^{\prime}}+P E_{\omega_{2}^{\prime}}\right)$

Go to engender $\delta 3 \in[0,1]$

Else

Engender $\delta 1, \delta 2 \in[0,1]$

$E d e c \leftarrow P E \omega+K E \omega+\delta 1 \delta 2 \times$ buffer $-\left(P E_{\omega_{1}^{\prime}}+P E_{\omega_{2}^{\prime}}\right)$

If $E d e c \geq 0$ then

Buffer $\longleftarrow$ buffer $\times(1-\delta 1 \delta 2)$

Engender $\delta 3 \in[0,1]$

$\left(K E_{\omega_{1}^{\prime}} \leftarrow E d e c \times \delta 3\right.$ and $K E_{\omega_{1}^{\prime}} \leftarrow E d e c \times(1-\delta 3)$

minimum structure $\omega_{1}^{\prime} \leftarrow \omega_{1}^{\prime}$

minimum structure $\omega_{2}^{\prime} \leftarrow \omega_{2}^{\prime}$

and

MinimumP $E_{\omega_{1}^{\prime}} \leftarrow \omega_{1}^{\prime}$ and MinimumP $E_{\omega_{2}^{\prime}} \leftarrow \omega_{2}^{\prime}$

Obliterate $M \omega$

Else

Number of Hitw $\leftarrow$ Number of Hitw +1

Obliterate $M \omega_{1}^{\prime}$ and $M \omega_{2}^{\prime}$

End if

End if

Inter-molecular ineffective collision operation: when two molecules collide with each other, then it dislocate the result, out $1(m, n)=\operatorname{in} 2(m, n)$, out $2(m, n)=\operatorname{in} 1(m, n)($ out $(m, n)$ is 2-dimensional output molecule, when in $(m, n)$ is 2dimensional input molecule).

Algorithm for intermolecular Ineffective Collision

Input: molecules $M \omega 1$ and $M \omega 2$

$\omega_{1}^{\prime} \leftarrow N(\omega 1)$ and $\omega_{2}^{\prime} \leftarrow N(\omega 2)$

$P E_{\omega_{1}^{\prime}} \leftarrow f\left(\omega_{1}^{\prime}\right)$ and $P E_{\omega_{2}^{\prime}} \leftarrow f\left(\omega_{2}^{\prime}\right)$

Number of Hit $\omega_{1} \leftarrow$ Number of Hit $\omega_{1}+1$ and Number of $\mathrm{Hit \omega}_{2} \leftarrow$ Number of Hit $\omega_{2}+1$

Einter $\leftarrow(\mathrm{PE} \omega 1+\mathrm{PE} \omega 2+\mathrm{KE} \omega 1+\mathrm{KE} \omega 2)-\left(P E_{\omega_{1}^{\prime}}+P E_{\omega_{2}^{\prime}}\right)$

If Einter $\geq 0$ then

Generate $\delta 4 \in[0,1]$

$K E_{\omega_{1}^{\prime}} \leftarrow$ Einter $\times \delta 4$ and $K E_{\omega_{2}^{\prime}} \leftarrow$ Einter $\times(1-\delta 4)$

$\omega 1 \leftarrow N\left(\omega_{1}^{\prime}\right)$ and $\omega 2 \leftarrow N\left(\omega_{2}^{\prime}\right)$

$P E \omega 1 \leftarrow P E \omega_{1}^{\prime}$ and $P E \omega 2 \leftarrow P E \omega_{2}^{\prime}$

$K E \omega 1 \leftarrow K E \omega_{1}^{\prime}$ and $K E \omega 2 \leftarrow K E \omega_{2}^{\prime}$

If $P E \omega 1<M i n P E \omega 1$ then

Minimum Struct $\omega 1 \leftarrow \omega 1$

Minimum $P E \omega 1 \leftarrow P E \omega 1$

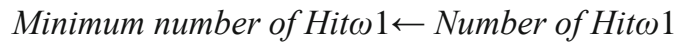

End if

If $P E \omega 2<M i n P E \omega 2$ then

Minimum Struct $\omega 2 \leftarrow \omega 2$

MinimumPE $\omega 2 \leftarrow P E \omega 2$ 
MinimimHitw2 $\leftarrow$ Number of Hitw2

End if

End if

Synthesis operation: it is a process of exactly opposite of decomposition. It merges two molecules into one molecule using out $(m, n)=i n 1(\mathrm{~m}, n)$ or out $(m, n)=i n 2(m, n)$.

Algorithm for synthesis operation

Input: molecules $M \omega 1$ and $M \omega 2$

Generate $M \omega^{\prime}$

Acquire $\omega^{\prime}$ from $\omega 1$ and $\omega 2$

$P E_{\omega^{\prime}} \leftarrow f\left(\omega^{\prime}\right)$

If $P E \omega 1+P E \omega 2+K E \omega 1+K E \omega 2 \geq P E \omega^{\prime}$ then

$K E \omega^{\prime} \leftarrow(P E \omega 1+P E \omega 2+K E \omega 1+K E \omega 2)-P E \omega^{\prime}$

Minimum Structure $\omega \leftarrow \omega^{\prime}$

Minimum $P E \omega_{1}^{\prime} \leftarrow P E \omega^{\prime}$

Obliterate $M \omega 1$ and $M \omega 2$

Else

Number of Hitw1 $\leftarrow$ Number of Hitw1+ 1 and Number of

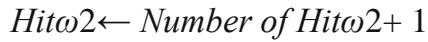

Obliterate $\omega^{\prime}$

End if

a. Begin

b. fundamental parameters are initialized

c. adjudicator random ( ) $>$ Molecule Collusion

d. adjudicator $K E \leq \delta$ when step (c) fulfilled

e. synthesis operation done when step (d) fulfilled

f. Inter-molecular ineffective collisions will take place

g. Synthesis operation is done when step (d) not fulfilled

h. do molecule selection procedure when if step (c) not fulfilled

i. adjudicator Number of Hit-Minimum number of Hit $>\gamma$

j. Do on-wall ineffective process

k. subsequently decomposition process has to be done

1. Test for minimum potential energy (PE)

m. When Current potential energy (PE) <parameter potential energy (PE) limit satisfied, then return to step (c) n. End

\section{SIMULATION RESULTS}

At first in standard IEEE 14 bus system the validity of the proposed algorithms has been tested $\&$ comparison results are presented in Table 1 . Real power loss has been considerably reduced \& vital parameters are within the limits.

Table 1. Comparison of real power loss

\begin{tabular}{cccc}
\hline Control variables & ABCO [23] & IABCO [23] & CRO \\
\hline V1 & 1.06 & 1.05 & 1.03 \\
V2 & 1.03 & 1.05 & 1.01 \\
V3 & 0.98 & 1.03 & 1.00 \\
V6 & 1.05 & 1.05 & 1.01 \\
V8 & 1.00 & 1.04 & 0.90 \\
Q9 & 0.139 & 0.132 & 0.100 \\
T56 & 0.979 & 0.960 & 0.900 \\
T47 & 0.950 & 0.950 & 0.900 \\
T49 & 1.014 & 1.007 & 1.000 \\
Ploss (MW) & 5.92892 & 5.50031 & 4.10212 \\
\hline
\end{tabular}

Then the Performance of the projected algorithm has been validated by tested in standard IEEE 57 bus system [24]. Total active and reactive power demands in the system are 1248.23 MW and 334.16 MVAR. Generator data the system is given in Table 2. The optimum loss comparison is presented in Table 3.

Table 2. Generator data

\begin{tabular}{ccccc}
\hline $\begin{array}{c}\text { Generator } \\
\text { No }\end{array}$ & $\begin{array}{c}\text { Pgi } \\
\text { minimum }\end{array}$ & $\begin{array}{c}\text { Pgi } \\
\text { maximum }\end{array}$ & $\begin{array}{c}\text { Qgi } \\
\text { minimum }\end{array}$ & $\begin{array}{c}\text { Qgi } \\
\text { maximum }\end{array}$ \\
\hline 1 & 25.00 & 50.00 & 0.00 & 0.00 \\
2 & 15.00 & 90.00 & -17.00 & 50.00 \\
3 & 10.00 & 500.00 & -10.00 & 60.00 \\
4 & 10.00 & 50.00 & -8.00 & 25.00 \\
5 & 12.00 & 50.00 & -140.00 & 200.00 \\
6 & 10.00 & 360.00 & -3.00 & 9.00 \\
7 & 50.00 & 550.00 & -50.00 & 155.00 \\
\hline
\end{tabular}

Table 3. Comparison of losses

\begin{tabular}{|c|c|c|c|c|c|c|c|c|}
\hline Parameter & $\begin{array}{c}\text { CLPSO } \\
{[26]}\end{array}$ & $\begin{array}{c}\text { DE } \\
{[25]}\end{array}$ & $\begin{array}{c}\text { GSA } \\
{[25]}\end{array}$ & $\begin{array}{c}\text { OGSA } \\
{[27]}\end{array}$ & $\begin{array}{c}\text { SOA } \\
{[26]}\end{array}$ & $\begin{array}{c}\text { QODE } \\
{[25]}\end{array}$ & $\begin{array}{l}\text { CSA } \\
{[28]}\end{array}$ & CRO \\
\hline PLOSS (MW) & 24.5152 & 16.7857 & 23.4611 & 23.43 & 24.2654 & 15.8473 & 15.5149 & 13.1264 \\
\hline
\end{tabular}

Then the performance of the proposed Algorithm has been tested in standard IEEE 300 bus system [24]. Table 4 shows the comparison of real power loss obtained after optimization.

Table 4. Comparison of real power loss

\begin{tabular}{ccccc}
\hline Parameter & EGA [29] & EEA [29] & CSA [28] & CRO \\
\hline PLOSS (MW) & 646.2998 & 650.6027 & 635.8942 & 623.2196 \\
\hline
\end{tabular}

\section{CONCLUSION}

In this paper, Chemical Reaction Optimization (CRO) algorithm successfully solved optimal reactive power problem. Candidate solution of reactive power flow problem is encoded as a molecule in Chemical Reaction Optimization (CO) algorithm. Gaussian perturbations with reflection, half-total change, laws of conservation of energy are formed as the prime operators in the Chemical Reaction Optimization (CRO) algorithm Search of the optimal solution has been improved.
Projected Chemical Reaction Optimization (CRO) algorithm has been tested in standard IEEE 14, 57, 300 bus systems. Simulation results indicate the better performance of the proposed algorithm in reducing the real power loss.

\section{REFERENCES}

[1] Lee, K.Y. (1984). Fuel-cost minimisation for both real andreactive-power dispatches. Proceedings Generation, Transmission and Distribution Conference, 131(3): 8593. https://doi.org/10.4236/oalib.1102464

[2] Monticelli, A., Pereira, M.V.F., Granville, S. (1987). Security constrained optimal power flow with post contingency corrective rescheduling. IEEE Transactions on Power Systems PWRS-2, (1): 175-182. https://doi.org/10.1109/TPWRS.1987.4335095

[3] Deeb, N.I. (1998). An efficient technique for reactive power dispatch using a revised linear programming approach. Electric Power System Research, 15(2): 121134. https://doi.org/10.1016/0378-7796(88)90016-8 
[4] Bjelogrlic, M.R., Calovic, M.S., Babic, B.S. (1990). Application of Newton's optimal power flow in voltage/reactive power control. IEEE Transactions on Power System, 5(4): 1447-1454. https://doi.org/10.1109/59.99399

[5] Granville, S. (1994). Optimal reactive dispatch through interior point methods. IEEE Transactions on Power System, $9(1):$

$136-146$ https://doi.org/10.1109/59.317548

[6] Grudinin, N. (1998). Reactive power optimization using successive quadratic programming method. IEEE Transactions on Power System, 13(4): 1219-1225. https://doi.org/10.1109/59.736232

[7] Wei, Y., Yu, J., Yu, D.C., Bhattarai, K. (2006). A new optimal reactive power flow model in rectangular form and its solution by predictor corrector primal dual interior point method. IEEE Transactions on Power System, 21(1):

61-67. https://doi.org/10.1109/TPWRS.2005.861978

[8] Canizares, C.A., de Souza, A.C.Z., Quintana, V.H. (1996). Comparison of performance indices for detection of proximity to voltage collapse. IEEE Transactions on Power $\quad$ Systems, 11(3): 1441-1450. https://doi.org/10.1109/59.535685

[9] Berizzi, C.B., Merlo, M., Delfanti, M. (2012). A GA approach to compare orpf objective functions including secondary voltage regulation. Electric Power Systems Research, 84(1):

187-194 https://doi.org/10.1016/j.epsr.2011.11.014

[10] Roy, P.S.G., Thakur, S. (2012). Optimal var control for improvements in voltage profiles and for real power loss minimization using biogeography based optimization. International Journal of Electrical Power and Energy Systems, $\quad 43(1)$ : 830-838 https://doi.org/10.1016/j.ijepes.2012.05.032

[11] Hu, Z., Wang, X., Taylor, G. (2010). Stochastic optimal reactive power dispatch: Formulation and solution method. International Journal of Electrical Power and Energy Systems, 32(6): 615-621. https://doi.org/10.1016/j.ijepes.2009.11.018

[12] Aparajita, M., Vivekananda, M. (2015). Solution of optimal reactive power dispatch by chaotic krill herd algorithm. IET Generation, Transmission, Distribution, 9(15): 2351-2362. https://doi.org/10.1049/ietgtd.2015.0077

[13] Hu, Z., Wang, X., Taylor, G. (2010). Stochastic optimal reactive power dispatch: Formulation and solution method. Electric Power Energy Systems, 32: 615-621. https://doi.org/10.1016/j.ijepes.2009.11.018

[14] Mahaletchumi, A.P.M., Rul, H.A., Mohd, H.S., Mahfuzah, M., Rosdiyana, S. (2016). Multi-objective evolutionary programming (MOEP) using mutation based on adaptive mutation operator (AMO) applied for optimal reactive power dispatch. ARPN Journal of Engineering and Applied Sciences, 11(14): 8884-8888.

[15] Pandiarajan, K., Babulal, C.K. (2016). Fuzzy harmony search algorithm based optimal power flow for power system security enhancement. International Journal Electric Power Energy Systems, 78: 72-79. https://doi.org/10.1016/j.ijepes.2015.11.053

[16] Mahaletchumi, M., Nor, R.H.A., Mohd, H.S., Mahfuzah, M., Rosdiyana, S. (2016). Benchmark studies on optimal reactive power dispatch (ORPD) based multi-objective evolutionary programming (MOEP) using mutation based on adaptive mutation adapter (AMO) and polynomial mutation operator (PMO). Journal of Electrical Systems, 12(1): 121-132.

[17] Shin Mei, N.G., Sulaiman, M.H., Mustaffa, Z. (2016). Ant lion optimizer for optimal reactive power dispatch solution. Journal of Electrical Systems, 67-74

[18] Gagliano, A., Nocera, F. (2017). Analysis of the performances of electric energy storage in residential applications. International Journal of Heat and Technology, 35(1): $\quad$ S41-S48. https://doi.org/10.18280/ijht.35Sp0106

[19] Caldera, M., Ungaro, P., Cammarata, G., Puglisi, G. (2018). Survey-based analysis of the electrical energy demand in Italian households. Mathematical Modelling of Engineering Problems, 5(3): 217-224. https://doi.org/10.18280/mmep.050313

[20] Leke, Z., Falah, Y.H.A., Adam, A.J. (2018). Concepts, methods, and performances of particle swarm optimization, backpropagation, and neural networks. Applied Computational Intelligence and Soft Computing, 9547212. https://doi.org/10.1155/2018/9547212

[21] Marina, B., Anton, K., Ilya, H., Alexander, S. (2017). A fuzzy classifier with feature selection based on the gravitational search algorithm. Symmetry, 2018(10): 609-609. https://doi.org/10.3390/sym10110609

[22] Xu, J., Lam, A.Y.S., Li, V.O.K. (2010). Parallel chemical reaction optimization for the quadratic assignment problem. In: Proceedings of the International Conference on Genetic and Evolutionary Methods, 125-131.

[23] Chandragupta, M.K.S., Subramanian, R., Purrnimaa, S.S.R. (2017). Reactive power optimization in a power system network through metaheuristic algorithms. Turkish Journal of Electrical Engineering \& Computer Science, 25: 4615-4623. https://doi.org/10.3906/elk1703-159.

[24] Power Systems Test Case Archive. http://www.ee.washington.edu/research/pstca, accessed on Feb. 12, 2018.

[25] Basu, M. (2016). Quasi-oppositionaldifferential evolution for optimal reactive power dispatch. Electrical Power and Energy Systems, 78: 29-40. https://doi.org/10.1016/j.ijepes.2015.11.067

[26] Dai, C. (2009). Seeker optimization algorithm for optimal reactive power dispatch. IEEE Transactions on Power System, 24(3): 1218-1231. https://doi.org/10.1109/TPWRS.2009.2021226

[27] Shaw, B. (2014). Solution of reactive power dispatch of power systems by an opposition-based gravitational search algorithm. International Journal of Electrical Power Energy Systems, 55: 29-40. https://doi.org/10.1016/j.ijepes.2013.08.010

[28] Reddy, S.S. (2017). Optimal reactive power scheduling using cuckoo search algorithm. International Journal of Electrical and Computer Engineering, 7(5): 2349-2356. https://doi.org/10.11591/ijece.v7i5.pp2349-2356

[29] Reddy, S.S. (2014). Faster evolutionary algorithm based optimal power flow using incremental variables. Electrical Power and Energy Systems, 54: 198-210. https://doi.org/10.1016/j.ijepes.2013.07.019 